\title{
Síndrome de Gianotti-Crosti o acrodermatitis papular de la infancia
}

\author{
Gianotti-Crosti syndrome or childhood \\ papular acrodermatitis
}

\author{
Larissa Dorina López-Cepeda, ${ }^{*}$ María Enriqueta Morales-Barrera, ${ }^{\ddagger}$ \\ José Alberto Ramos-Garibay, ${ }^{\S}$ Yuriko Calderón-Ponce de León*
}

\section{RESUMEN}

El síndrome de Gianotti-Crosti es una dermatosis infantil frecuente y autolimitada que afecta a niños entre seis meses y 12 años de edad, con un pico máximo entre el primero y el sexto año de vida; sin embargo, existen escasos reportes de su presentación en adultos. Se le considera un tipo de reacción cutánea asociado con virus, bacterias y vacunas. En el presente artículo se analiza el caso de un paciente masculino con acrodermatitis papular de la infancia, de tres semanas de evolución, con involucro de piel cabelluda y lesiones de aspecto vesículoampolloso, lo que dificultó inicialmente su diagnóstico clínico, ya que el diagnóstico clínico diferencial debe realizarse con histiocitosis.

Palabras clave: Síndrome de Gianotti-Crosti, acropapulosis de la infancia.

\section{ABSTRACT}

Gianotti-Crosti syndrome is a common childhood and self-limited dermatosis that affects children from 6 months to 12 years old, with a peak between the first and sixth years of life. However there are a few reports in adults. It represents a pattern of skin reaction to viruses, bacteria and vaccines. This article analyzes the case of a male patient with papular acrodermatitis of childhood, with an evolution of three weeks. This dermatosis affected the scalp with vesiculo-papular lesions which difficulted the clinical diagnosis, since the differential diagnosis must be done with histiocytosis.

Keywords: Gianotti-Crosti syndrome, infantile papular acrodermatitis, papular acrodermatitis of childhood.

\section{REVISIÓN DE LA LITERATURA}

El síndrome de Gianotti-Crosti (Sx G-C), también conocido como acropapulosis de la infancia o acrodermatitis papular infantil, fue descrito por primera vez por Gianotti en 1955. Es una dermatosis relativamente común y autolimitada ${ }^{1}$ que afecta a niños sin distinción de género, desde los seis meses hasta los 12 años de edad, con un pico de mayor incidencia entre el primero y el sexto año

\footnotetext{
* Dermatóloga.

‡ Responsable de Servicio de Dermatología Pediátrica.

$\S$ Dermatopatólogo.
}

de vida. ${ }^{2}$ Se han publicado casos en jóvenes y adultos, siendo las mujeres más afectadas en este último grupo. ${ }^{3,4}$ Este padecimiento se encuentra subdiagnosticado, por lo que se desconoce su prevalencia exacta.

EI Sx G-C surge como un patrón de reacción cutánea, secundario a infección por virus, bacterias y vacunas. Se presenta varias semanas posteriores a la resolución de estas infecciones. ${ }^{2}$ Los virus más frecuentemente involucrados son: hepatitis B (VHB) variedad a y w,

Citar como: López-Cepeda LD, Morales-Barrera ME, Ramos-Garibay JA, CalderónPonce de León Y. Síndrome de Gianotti-Crosti o acrodermatitis papular de la infancia. Rev Cent Dermatol Pascua. 2020; 29 (1): 20-25. https://dx.doi.org/10.35366/96266 
Epstein-Barr (VEB), enterovirus, sincicial respiratorio, rotavirus, adenovirus, echovirus, poxvirus, poliovirus, coxsackievirus, parvovirus, inmunodeficiencia humana, hepatitis $C$, parainfluenza, y con menor frecuencia se asocia a citomegalovirus (CMV). De las bacterias Mycoplasma pneumoniae sp., Borrelia sp., Bartonella $s p$. y Streptococcus $\beta$ del grupo hemolítico son las más frecuentes. De las vacunas se le ha vinculado con: influenza, difteria, tétanos, pertussis, BCG, vacuna oral contra polio y hepatitis tipo A (VHA) y B (VHB) ${ }^{5,6}$

Se sugiere que las lesiones en el Sx G-C pueden ser consecuencia de antigenemia viral o por la acción de complejos inmunes circulantes; no obstante, se prefiere la primer teoría, ya que en varias ocasiones se ha observado que el tiempo entre la infección viral y la presencia del Sx G-C no es suficiente como para dar lugar a la formación de complejos antígeno anticuerpo.

Se han detectado partículas semejantes a virus en las vacuolas citoplásmicas y lisosomas en la piel de estos pacientes, lo que sugiere que probablemente el virus se reproduce en la piel y órganos linfoides. El infiltrado inflamatorio perilesional está constituido por células dendríticas y linfocitos T CD4, sugestivo de hipersensibilidad tipo IV inducida por virus. Otra teoría señala que existe una predisposición genética a desarrollar este padecimiento debido a que el huésped cursa con alteraciones inmunes y/o dermatitis atópica.7,8

Dentro de las características clínicas se ha descrito que previo al establecimiento del exantema, existe el antecedente de haber cursado con un pródromo inespecífico de infección viral, ya sea de vías aéreas superiores o gastrointestinales asociado a fiebre.

Característicamente los pacientes desarrollan lesiones múltiples, de 1 a 10 mm de diámetro, monomorfas, constituidas por pápulas café rojizo planas o cupuliformes, ocasionalmente papulovesículas pruriginosas, raramente hemorrágicas, que se agrupan formando grandes placas. Se distribuyen simétricamente en mejillas, superficies extensoras de extremidades y nalgas; generalmente respeta tronco, plantas y palmas. El fenómeno de Koebner se puede presentar en fases tempranas. Evoluciona en pocos días, persistiendo el exantema, con descamación en dos a ocho semanas; resuelve espontáneamente sin dejar cicatriz. ${ }^{2,9}$

Los síntomas físicos relacionados con Sx G-C son: malestar general, febrícula y diarrea moderados; puede cursar con linfadenopatía entre 25 y $35 \%$ de los enfermos, especialmente a nivel cervical, axilar e inguinal así como hepatomegalia asociada a VHB. ${ }^{4,8}$

Se ha propuesto una serie de criterios diagnósticos para el Sx G-C, los cuales se resumen en la Tabla 1.
No existen exámenes de laboratorio específicos que corroboren el diagnóstico clínico presuntivo, por lo que el diagnóstico se basa en las características clínicas.

En individuos con hepatomegalia se deben solicitar biometría hemática completa y enzimas hepáticas; si éstas últimas se encuentran elevadas, se deben solicitar intencionadamente pruebas de confirmación de VHA y VEB. Si se sospecha de hepatitis se deben buscar anticuerpos $\lg \mathrm{G}$ e $\lg \mathrm{M}$ antihepatitis $\mathrm{A}$, antígeno de superficie de hepatitis $\mathrm{B}$ e IgG anti-VHC. La linfocitosis es común y no requiere evaluaciones posteriores.

Los hallazgos histológicos en sujetos con Sx G-C tampoco son específicos: se aprecia hiperqueratosis leve, espongiosis, hiperplasia psoriasiforme en epidermis, infiltrado linfohistiocitario de la dermis superior con una distribución perivascular o liquenoide. , $^{3,4,6,9}$

Los diagnósticos diferenciales más frecuentes son:

1. Liquen plano: se caracteriza por prurito intenso, afección de mucosas, y de la cara anterior de muñecas, las lesiones son de color violeta pálido. Es muy raro el compromiso de mejillas.

2. Reacciones liquenoides por fármacos: son poco frecuentes en los niños, suele comprometer el tronco;

3. Eritema multiforme: es más frecuente en adolescentes y adultos, con lesiones característicamente en tiro al blanco, que se ubican en extremidades, acompañadas de signos y síntomas sistémicos, generalmente provocados por diversas patologías.

\section{Tabla 1: Criterios diagnósticos del Sx G-C}

Al menos en una revisión clínica se encuentra con todas las características clínicas positivas:

Morfología monomorfa constituida por pápulas color rosa-café 0 papulovesículas de superficie plana, de $1-10 \mathrm{~mm}$ de diámetro Topografía simétrica en al menos tres de los siguientes cuatro lugares: mejillas, nalgas, superficies extensoras de los antebrazos y superficies extensoras de las piernas

Duración de al menos 10 días

En todas las revisiones clínicas el paciente no presenta características clínicas negativas:

Lesiones truncales extensas

Lesiones con escama

Ninguno de los diagnósticos diferenciales (acrodermatitis enteropática, eritema infeccioso, eritema multiforme, enfermedad mano-pieboca, púrpura de Henoch-Schönlein, enfermedad de Kawasaki, liquen plano, urticaria papular, síndrome papular purpúrico en guante y calcetín, sarna) se considera más probable que el GCS en el juicio clínico

Biopsia lesional consistente con el Sx G-C 
4. Escabiasis: caracterizada por pápulas predominantemente acrales, muy pruriginosas, con excoriaciones localizadas en pezones, glande, ombligo, con asociación de sintomatología familiar.

5. Prurigo simple o prurigo por insectos: caracterizado por pápulas muy pruriginosas agrupadas, generalmente en las superficies de extensión de las extremidades.

6. Enfermedades exantemáticas como mano-pie-boca, la quinta enfermedad y el síndrome papular purpúrico en guante y calcetín. ${ }^{10}$

7. Histiocitosis: de particular importancia como diagnóstico diferencial en el caso que nos ocupa, constituyen un grupo de enfermedades raras, hereditarias y reactivas, con un amplio espectro en cuanto a severidad. El cuadro clínico varía desde enfermedad localizada y autolimitada hasta generalizada y fatal. Los sitios más comúnmente afectados son la cabeza, el tronco y los pliegues. Las lesiones en mucosas dañan la boca y los genitales, generalmente se manifiesta con lesiones de aspecto nodular, ulceradas. Coexiste con diabetes insípida y exoftalmus. ${ }^{11}$ Las lesiones sistémicas pueden afectar huesos, hígado, médula ósea, pulmones, bazo y nódulos linfáticos. En la histopatología se observa un infiltrado denso constituido por histiocitos, con un intenso epidermotropismo. La estructura patognomónica es la presencia de la célula de Langerhans, la cual representa a un histiocito profesional, con un núcleo irregular, arriñonado y citoplasma levemente eosinofí-

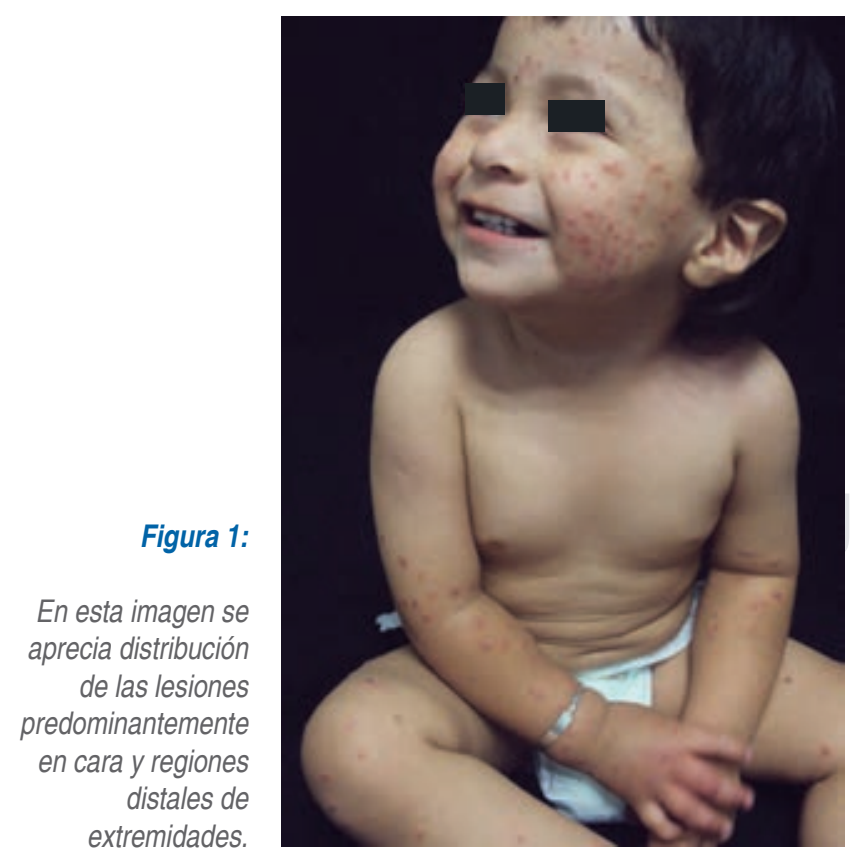

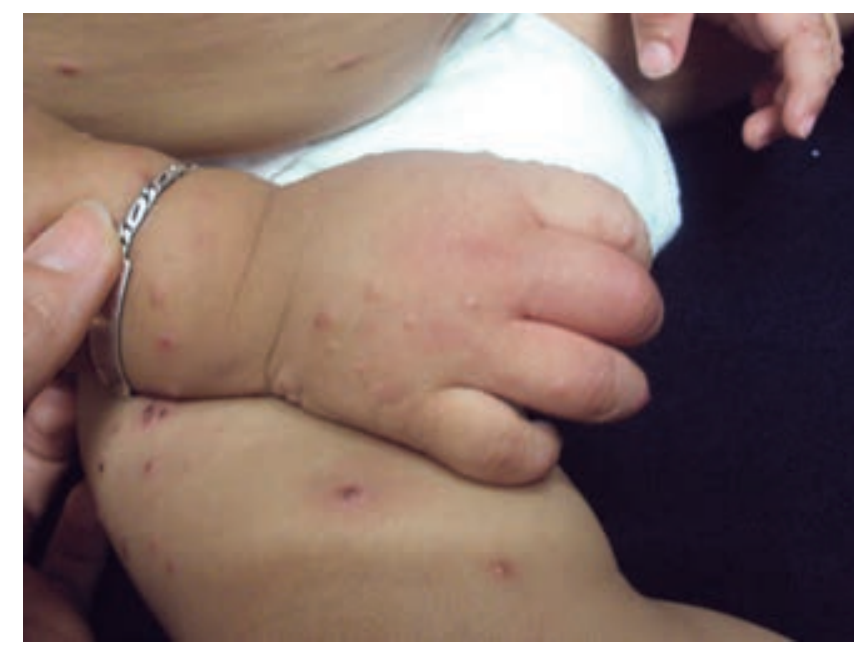

Figura 2: Pápulas excoriadas, de localización característica en extremidades.

lico y abundante. Estas células son positivas para la proteína S100, CD1a y CD207, además contienen los típicos gránulos de Birbeck o en raqueta de tenis. ${ }^{12}$

El tratamiento es únicamente sintomático contra el prurito. Se sugiere el uso de emolientes tópicos con calamina; en casos moderados pueden emplearse antihistamínicos o esteroides tópicos de mediana potencia por una o dos semanas. En casos severos se pueden administrar corticoides sistémicos en pulsos; sin embargo, no existe evidencia de que modifiquen el curso de la enfermedad. ${ }^{13}$

El pronóstico para los pacientes con Sx G-C en la mayoría de los casos es bueno, ya que se autolimita. El curso es variable, dura entre cinco días y 12 meses. Habitualmente las lesiones se curan sin dejar cicatriz. La complicación más frecuente es la hipopigmentación o hiperpigmentación postinflamatoria en fototipos cutáneos con piel oscura, y la complicación más grave es la falla hepática asociada a infección por VHB o VEB. La linfadenopatía puede durar meses. ${ }^{8}$

\section{CASO CLÍNICO}

Paciente del sexo masculino, de un año ocho meses de edad, quien es traído por su madre a consulta por presentar «granitos» en manos y pies, de tres semanas de evolución, los cuales se extendieron a cara, ocasionándole edema facial.

A la exploración física se observa una dermatosis diseminada a cabeza, tronco y extremidades superiores 
e inferiores. De cabeza, afecta piel cabelluda en vértex, y cara, respetando párpados y labios. De tronco, afecta región dorso lumbar. De extremidades superiores, afecta los 2/3 distales de brazos, antebrazos, manos y palmas. De extremidades inferiores, sólo respeta parte del tercio proximal de muslos, sobre la cadera; bilateral, con tendencia a la simetría (Figura 1). Se trata de una dermatosis de aspecto monomorfo, polilesional en varios estadios, constituida por pápulas eritematosas decapitadas por rascado, papulovesículas, vesículas y manchas eritematosas de 2-3 mm de diámetro (Figuras 2 y 3).

Al interrogatorio la madre refirió tratamiento previo con nitazoxanida, trimetoprima/sulfametoxazol, loratadina, baño coloide y emolientes con ácido láctico y urea, sin mejoría.
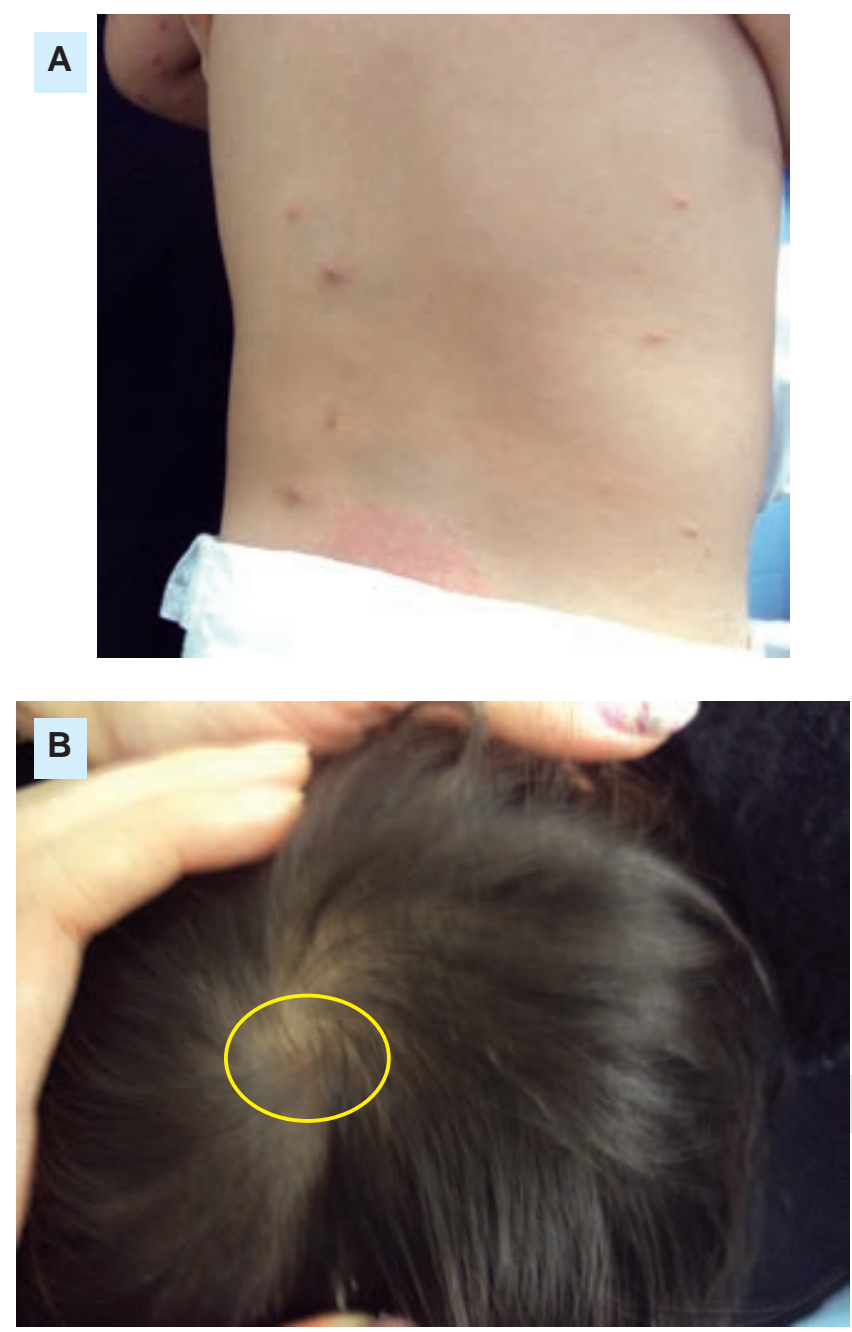

Figura 3: Se observa dermatosis diseminada a sitios poco frecuentes como tronco $\boldsymbol{A}$ ) y piel cabelluda $\boldsymbol{B}$ ).
Figura 4:

Epidermis con mínima acantosis. Dermis superficial y media con vasos dilatados $y$ congestionados rodeados por un leve infiltrado inflamatorio ( $H \& E$,

$4 x)$.

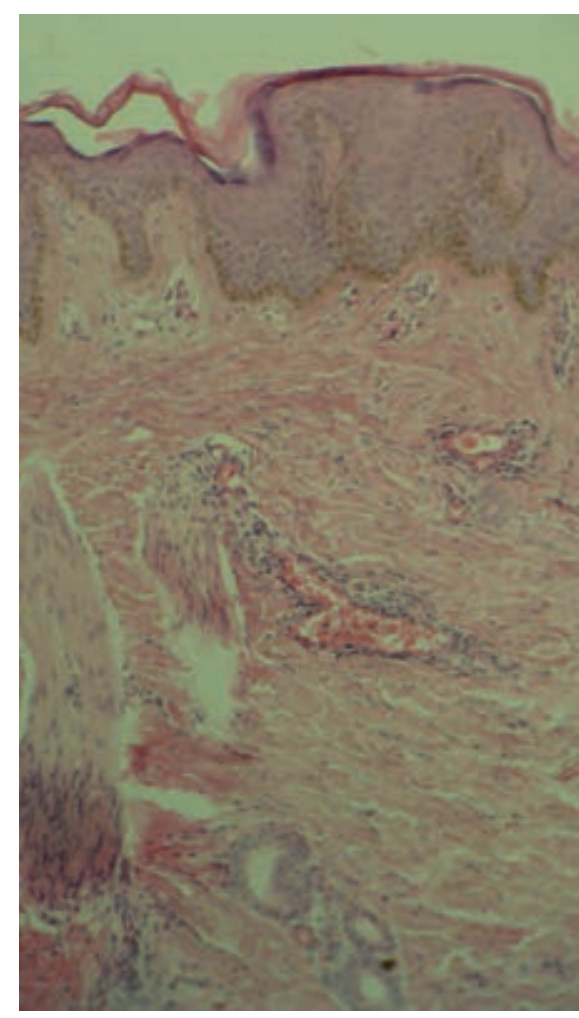

Figura 5:

En la dermis superficial se observan discretos infiltrados de linfocitos $y$ eosinófilos perivasculares (H\&E 10x). 
Tabla 2: Perfil viral para hepatitis A y B

(proporcionado por la madre del paciente).

Marcadores de hepatitis A

Anticuerpos Ig M Negativo

Anticuerpos lgG Negativo

Marcadores de hepatitis B

Anticuerpos contra el antígeno de superficie Reactivo

Antígeno de superficie

No reactivo

Anticuerpos contra el antígeno $\mathrm{E} \quad$ No reactivo

Antígeno $\mathrm{E}$

No reactivo

Core total

Anticuerpos core $\mathrm{M}$

No reactivo

No reactivo

Tabla 3: Perfil viral para virus Epstein-Barr.

Marcadores de virus Epstein-Barr

\begin{tabular}{|c|c|c|}
\hline $\begin{array}{l}\text { Antígeno de la cápside } \\
\text { viral IgM (VCAM) }\end{array}$ & $33.5 \mathrm{U} / \mathrm{mL}$ & $\begin{array}{l}\text { 0-19: negativo } \\
\text { 20-40: indeterminado } \\
>\text { 40: positivo }\end{array}$ \\
\hline $\begin{array}{l}\text { Antígeno de la cápside } \\
\text { viral lgG (VCAG) }\end{array}$ & $>750 \mathrm{U} / \mathrm{mL}$ & $\begin{array}{l}\text { 0-19: negativo } \\
>20 \text { : positivo }\end{array}$ \\
\hline $\begin{array}{l}\text { Antígeno temprano } \\
\text { difuso } \lg G(E A d)\end{array}$ & $33.8 \mathrm{U} / \mathrm{mL}$ & $\begin{array}{l}\text { 0-9: negativo } \\
\text { 10-40: indeterminado } \\
>\text { 40: positivo }\end{array}$ \\
\hline $\begin{array}{l}\text { Antígeno nuclear } \\
\text { inducido IgG (EBNA) }\end{array}$ & $\begin{array}{r}45.2 \\
\mathrm{U} / \mathrm{mL}\end{array}$ & $\begin{array}{l}\text { 0-4: negativo } \\
\text { 5-20: indeterminado } \\
>20 \text { : positivo }\end{array}$ \\
\hline
\end{tabular}

Con el diagnóstico clínico presuntivo de probable histiocitosis se realizó estudio histopatológico y se le prescribieron emolientes y antihistamínico vía oral.

A las dos semanas se solicitó interconsulta al Servicio de Dermatología Pediátrica del Centro Dermatológico «Dr. Ladislao de la Pascua». En ese momento la dermatosis se había modificado, observándose únicamente lesiones a nivel de mejillas, antebrazos y piernas, con numerosas pápulas eritematosas, algunas decapitadas, con costra sanguínea o hemática, y otras con costras melicéricas, por lo que la sospecha diagnóstica se orientó hacia acropapulosis de la infancia.

El estudio histopatológico mostró una epidermis con discreta acantosis. Dermis superficial y media con discretos infiltrados de linfocitos y eosinófilos perivasculares. Se observan también vasos capilares dilatados y congestionados; datos compatibles con síndrome de Gianotti-Crosti (Figuras 4 y 5).
Para completar dicho diagnóstico se solicitó un perfil viral para los virus de hepatitis A y B (Tabla 2) y Epstein-Barr (Tabla 3) así como pruebas de función hepática (Tabla 4).

Los resultados demuestran la presencia de anticuerpos IgG contra el antígeno de la cápside viral para Epstein-Barr positivo, haciendo referencia a una infección previa por dicho virus. Por otra parte, la reactividad de anticuerpos contra el antígeno de superficie del virus hepatitis B significa una adecuada respuesta inmunológica ante la vacuna contra éste, previamente aplicada. Tanto la infección precedente por virus Epstein-Barr como la inmunización ante el virus de hepatitis B pueden haber actuado como desencadenantes del Sx G-C en este paciente.

Se inició tratamiento conservador con emolientes tópicos y vigilancia, con lo cual se obtuvo mejoría paulatina. Se mantiene al enfermo en observación periódica para descartar complicaciones a largo plazo.

\section{COMENTARIO}

De los criterios propuestos para el diagnóstico del Sx G-C, el caso del paciente, motivo de esta publicación, presentaba morfología habitual (papulovesículas eritematosas sin escama) de más de 10 días de evolución, con topografía habitual y fuera de la habitual (en piel cabelluda, palmas y plantas), lo cual hizo difícil realizar inicialmente el diagnóstico; sin embargo, presentaba afección en tres de las cuatro áreas establecidas en los criterios propuestos por Chuh de manera predominante en las cuatro extremidades. ${ }^{2}$

Asimismo, se excluyeron otras posibles patologías. ${ }^{8}$

Con respecto a la histiocitosis, clínicamente el enfermo no presentaba lesiones en mucosas; en el estudio histopatológico no se observaron células de Langerhans sugestivas; la epidermis se encontró con discreta acantosis; dermis superficial y media con discretos

\section{Tabla 4: Pruebas de función hepática.}

$\begin{array}{lcc}\text { Fosfatasa alcalina } & 317 \mathrm{U} / \mathrm{L} & 55-375 \mathrm{U} / \mathrm{L} \\ \text { Bilirrubina total } & 0.23 \mathrm{mg} / \mathrm{dL} & 0.5-1.50 \\ \text { Bilirrubina directa } & 0.03 \mathrm{mg} / \mathrm{dL} & 0-0.25 \\ \text { Bilirrubina indirecta } & 0.20 \mathrm{mg} / \mathrm{dL} & 0.05-1.00 \\ \text { Proteínas totales } & 7.4 \mathrm{~g} / \mathrm{dL} & 6-8.20 \\ \text { Albúmina } & 4.2 \mathrm{~g} / \mathrm{dL} & 3.4-5.00 \\ \text { Globulina } & 3.2 \mathrm{~g} / \mathrm{dL} & 0.3-3.5 \\ \text { Alanino aminotransferasa } & 38 \mathrm{U} / \mathrm{L} & 3-50.00 \\ \text { Aspartato aminotransferasa } & 40 \mathrm{U} / \mathrm{L} & 5-80.00\end{array}$


infiltrados de linfocitos y eosinófilos perivasculares. Por la evolución clínica y el antecedente de infección por VEB, y haciendo correlación clínico histopatológica, el resultado en este caso fue síndrome de Gianotti-Crosti.

El gran problema con el que se enfrenta el dermatólogo es que en del Sx G-C no existe un cuadro clínico característico de dicha enfermedad, motivo por el cual está subdiagnosticado. Teniendo como base los datos arriba señalados, exhortamos a los lectores a reflexionar en esta patología, que si bien es de curso benigno, puede asociarse a infecciones subyacentes de cierta gravedad como la ocasionada por virus Epstein-Barr y la hepatitis. Se debe realizar búsqueda intencionada, y vigilar minuciosamente la evolución de los enfermos para evitar complicaciones. ${ }^{1,3,10}$

\section{BIBLIOGRAFÍA}

1. Gümüş $P$, Tekşam Ö, Akinci H, Boztepe G, Kara A. Gianotti-Crosti syndrome as the only manifestation of primary Epstein-Barr virus infection: a case report. Turk J Pediatr. 2008; 50: 302-304.

2. Chuh AA. Diagnostic criteria for Gianotti-Crosti syndrome: a prospective case-control study for validity assessment. Cutis. 2001; 68: 207-213

3. Monastirli A, Varvarigou A, Pasmatzi E, Badavanis G, Georgiou S, Mantagos S et al. Gianotti-Crosti syndrome after hepatitis A vaccination. Acta Derm Venereol. 2007; 8: 174-175.

4. Gibbs S, Burrows NP. Gianotti-Crosti syndrome in two unrelated adults. Blackwell Science Ltd X. Clinical and Experimental Dermatology. 2000; 25: 594-596.
5. Kolivras A, André J. Gianotti-Crosti syndrome following hepatitis A vaccination. Pediatr Dermatol. 2008; 25: 650.

6. Hyun KN, Eun KJ, Kee CB, Jeong PH. Gianotti-Crosti syndrome following novel influenza A (H1N1) vaccination. Ann Dermatol. 2011; 23: 554-555.

7. Erkek E, Senturk GB, Özkaya Ö, Bükülmez G. Gianotti-Crosti syndrome preceded by oral polio vaccine and followed by varicella infection. Pediatr Dermatol. 2001; 18: 516-518.

8. Brandt O, Abeck D. Gianotti-Crosti syndrome. J Am Acad Dermatol. 2006; 54: 136-145.

9. Murphy LA, Buckley C. Gianotti-Crosti syndrome in an infant following immunization. Pediatr Dermatol. 2000; 17: 225-226.

10. Chuh A, Zawar V, Law M, Sciallis G. Gianotti-Crosti syndrome, pityriasis rosea, symmetrical periflexural exanthem, unilateral mediothoracic exanthem, eruptive pseudoangiomatosis, and papularpurpuric gloves and socks syndrome: a brief review and arguments for diagnostic criteria. Infect Dis Rep. 2012; 4: e12.

11. Grois N, Pötschger U, Prosch H, Minkov M, Arico M, Braier J et al. Risk factors for diabetes insipidus in Langerhans cell histiocytosis. Pediatr Blood Cancer. 2006; 46: 228-233.

12. Newman B, HuW, Nigro K, Gilliam AC. Aggressive histiocytic disorders that can involve the skin. J Am Acad Dermatol. 2007; 56: 302-316.

13. Boeck K, Mempel M, Schmidt T, Abeck D. Gianotti-Crosti syndrome: clinical, serologic, and therapeutic data from nine children. Cutis. 1998; 62: 271.

Correspondencia:

Dra. Larissa Dorina López Cepeda

Dr. Vértiz Núm. 464, Esq. Eje 3 Sur,

Col. Buenos Aires, 06780,

Alcaldía Cuauhtémoc, CDMX.

Tel: 55 5538-7033 y 55 5519-6351.

E-mail: larisslo@yahoo.com.mx 